\title{
External fixator combined with three different fixation methods of fibula for treatment of extra-articular open fractures of distal tibia and fibula: a retrospective study
}

Dong-Dong Sun ${ }^{1,2+}$, Dan $\mathrm{Lv}^{1+}$, Kun Zhour ${ }^{2 \dagger}$, Jian Chen ${ }^{2}$, Li-Lan Gao ${ }^{3 *}$ and Ming-Lin Sun ${ }^{1 *}$

\begin{abstract}
Background: To compare the efficacy of three different fixation methods of fibula combined with external fixation of tibia for the treatment of extra-articular open fractures of distal tibia and fibula.

Methods: From January 2017 to July 2019, 91 cases of open fractures of distal tibia and fibula were treated with external fixator, and the fibula was fixed with non-fixation (group A, $n=35$ ), plate-screw (group $B, n=30$ ) and Kirschner wire (group $C, n=26$ ). The operation time, intraoperative blood loss, surgical and implants costs, fracture healing time, postoperative complications, and American Orthopaedic Foot and Ankle surgery (AOFAS) scores were compared among the groups.

Results: Four patients were lost to follow-up, and 87 patients were followed up for 5-35 months (average, 14.2 months). The operation time of group C (114.92 $\pm 36.09 \mathrm{~min})$ was shorter than that of group A (142.27 $\pm 47.05 \mathrm{~min})$ and group $B(184.00 \pm 48.56 \mathrm{~min})(P<0.05)$. There was no difference in intraoperative blood loss among the three groups $(P>0.05)$. The surgical and implants costs in group $C(5.24 \pm 1.21$, thousand dollars) is lower than that in group A (6.48 \pm 1.11 , thousand dollars) and group B $(9.37 \pm 2.16$, thousand dollars $)(P<0.05)$. The fracture healing time of group C ( $5.67 \pm 1.42$ months) was significantly less than that of group $A(6.90 \pm 1.33$ months) and group $B$ (6.70 \pm 1.12 months) $(P<0.05)$. The postoperative complications such as fractures delayed union and nonunion in group C (2 cases, 8.00\%) is less than that in group A (13 cases, 39.39\%) and group B (11 cases, 37.93\%) $(P<0.05)$. The wound infection and needle-tract infection did not differ among the three groups $(P>0.05)$. The excellent or good rate of ankle function was $69.70 \%$ in group $A, 72.41 \%$ in group B and $84.00 \%$ in group C, with no statistical difference among the three groups $(P>0.05)$.

(Continued on next page)
\end{abstract}

\footnotetext{
*Correspondence: gaolilan780921@163.com; 165318413@qq.com

${ }^{\dagger}$ Dong-Dong Sun, Dan Lv and Kun Zhou contributed equally to this work.

${ }^{3}$ School of Mechanical Engineering, Tianjin University of Technology, No. 391

Bin Shui West Road, Tianjin 300384, China

'Department of Orthopedic, Characteristic Medical center of Chinese

People's Armed Police Force, No. 220 Cheng Lin Road, Tianjin 300171, China

Full list of author information is available at the end of the article
}

C C The Author(s). 2020 Open Access This article is licensed under a Creative Commons Attribution 4.0 International License, which permits use, sharing, adaptation, distribution and reproduction in any medium or format, as long as you give appropriate credit to the original author(s) and the source, provide a link to the Creative Commons licence, and indicate if changes were made. The images or other third party material in this article are included in the article's Creative Commons licence, unless indicated otherwise in a credit line to the material. If material is not included in the article's Creative Commons licence and your intended use is not permitted by statutory regulation or exceeds the permitted use, you will need to obtain permission directly from the copyright holder. To view a copy of this licence, visit http://creativecommons.org/licenses/by/4.0/. The Creative Commons Public Domain Dedication waiver (http://creativecommons.org/publicdomain/zero/1.0/) applies to the data made available in this article, unless otherwise stated in a credit line to the data. 
(Continued from previous page)

Conclusion: Compared with simple external fixator fixation and external fixator combined with plate-screw osteosynthesis, external fixator combined with K-wire intramedullary fixation shortens the operative time and fracture healing time, reduced costs and complications of fracture healing, while the blood loss, infection complications and ankle function recovery showed no difference with the other two groups. External fixator combined with plate-screw osteosynthesis had no advantage in treating extra-articular open fractures of distal tibia and fibula when compared with simple external fixation.

Keywords: Tibial fractures, Fibula, Fractures, open, External fixator, Kirschner wire

\section{Background}

Open fractures of distal tibia associated with fibula are usually caused by high-energy trauma such as traffic accidents or falling from high places. Till now it is still a big challenge to treat it because of the wound contamination, limited soft tissue envelope and poor vascularity. The role of fibular fixation in the treatment of distal tibiofibular syndesmosis injury and pilon fractures has been well defined [1,2], however, it is still controversial whether the fracture of fibular needs fixation and which method is selected in extra-articular fractures of the lower leg [3-5].

Bonnevialle [6] conducted a prospective cohort study, 126 cases of patients with distal tibia and fibula fractures were treated by fixing tibia with external fixator, intramedullary nail or plates, while fibula is not fixed, or fixed with intramedullary nail or plates. The results showed that fibula fixation was helpful to restore tibial length, reduce lateral movement of fracture and maintain the stability of the tibia in shaft direction. However, some other studies found that standard open reduction and internal fixation of tibia with intramedullary nail or minimally invasive percutaneous plate osteosynthesis (MIPPO), without the fibula being fixed, had good reduction stability of tibial fracture, reduced the risk of soft tissue injury and infection, and had a good prognosis of function [7-9]. Javdan [10] reported that dynamic compression bone plate (DCP) or tubular plate fixation of fibula had no significant difference in influence on tibial fracture healing, reduction of postoperative complications and recovery of affected limb function. In addition, a few studies have shown that fibular plate internal fixation can increase the rate of delayed healing and non-healing of tibial fractures [1]. In summary, in previous studies on the fixation of fibula fractures was with plate-screw internal fixation, elastic intramedullary nail or non-fixation, no attempt has been made to fix the fibula with Kirschner wires (K-wires).

External Fixators always is indicated in open fractures, they are advised in periarticular unstable fractures, floating knee injuries or most commonly in compound fractures in diaphyseal area [11-13]. Besides they are also commonly used always in limited economic reality [14].
The purpose of this study was to compare the efficacy of simple external fixation, external fixation combined with plate-screw osteosynthesis, external fixation combined with K-wire internal fixation for the treatment of extra-articular open fractures of distal tibia and fibula. The operation time, intraoperative blood loss, surgical and implants costs, fracture healing time, postoperative complications, and American Orthopaedic Foot and Ankle Surgery (AOFAS) scores were compared among the groups (Fig. 1).

\section{Methods \\ Materials}

External fixators (Hoffmann $\mathrm{II}^{\circ}$, Wuhan Constant Science and Technology Ltd. Hubei, China), steel plate and screws (Beijing BEST BIO Technical Co., Ltd. Beijing, China), K-wire (Suzhou Gemmed Medical Instrument Co., Ltd. Jiangsu, China), vacuum sealing drainage devices (VSD) (Wuhan VSD Medical Science and Technology Co. Ltd. Hubei, China).

\section{Patients}

The inclusion criteria for this study is as follow: (1) open fracture of distal tibia and fibula, fracture type: AO-42; (2) surgical methods: simple external fixation, external fixation combined with plate-screw osteosynthesis, external fixation combined with K-wire intramedullary fixation; (3) regular follow-up. Exclusion criteria: (1) ankle joint surface damaged severely, normal correspondence congruence and joint space can't be restored through fixation; (2) associated with serious hypertension, heart disease and other serious diseases, reduced operative-tolerance; (3) associated with brain and spinal nerve functional impairment, severely affected the function of the lower limbs; (4) previous history of severe degenerative arthritis, rheumatoid arthritis, cerebral infarction, and dyskinesia in the lower extremities.

From January 2017 to July 2019, 91 cases of open fractures of distal tibia and fibula were enrolled into this study, among which 35 patients were treated by simple external fixation (group A, $n=35$ ), 30 patients were treated by external fixation combined with plate-screw osteosynthesis (group B, $n=30$ ), and 26 patients were 


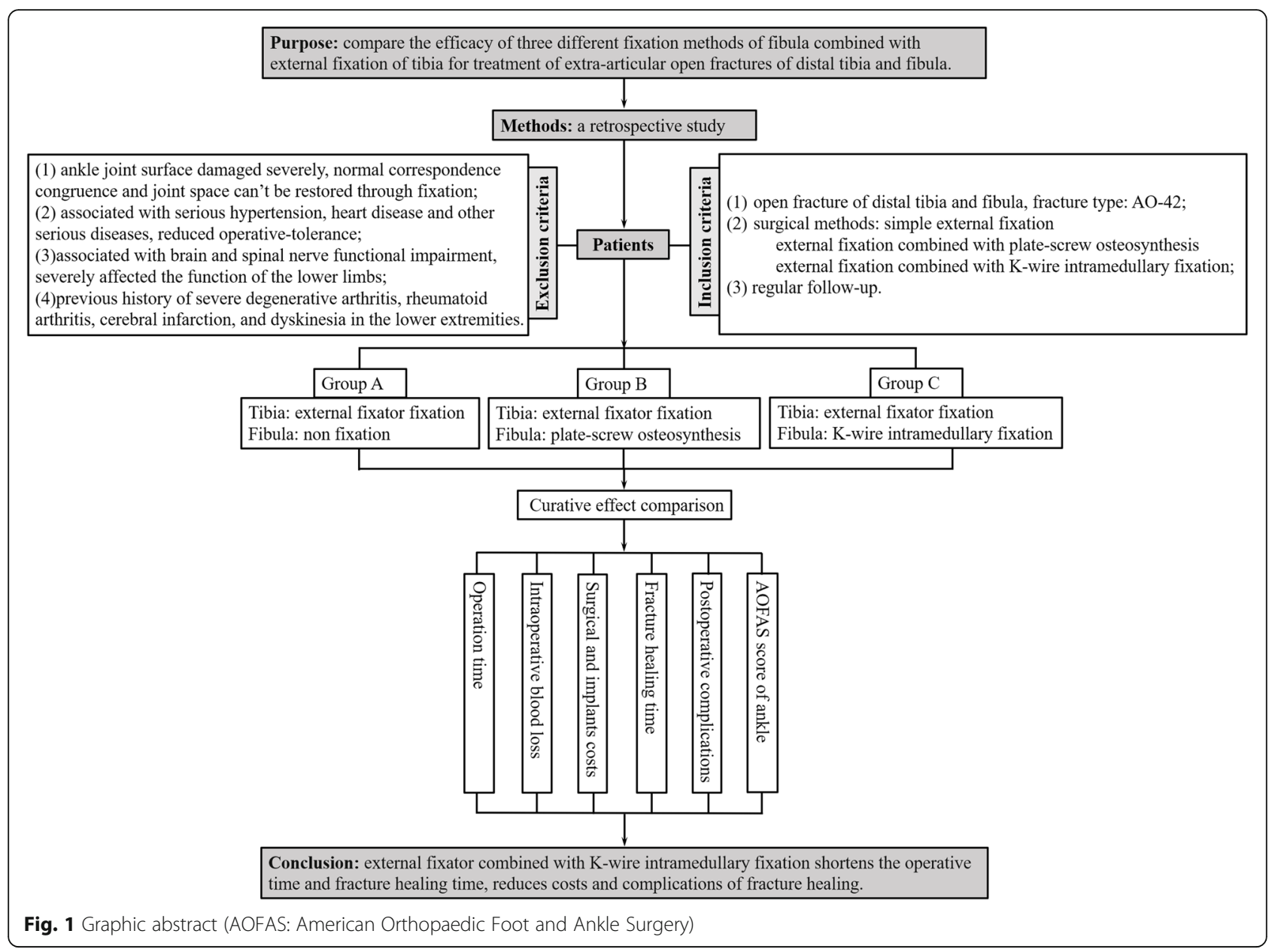

treated by external fixation combined with K-wire (2.0$3.0 \mathrm{~mm}$ ) intramedullary fixation (group C, $n=26$ ). There was no significant difference in gender, age, cause of injury, Gustilo classification and $\mathrm{AO}$ classification among the three groups $(P>0.05)$ (Table 1$)$.

\section{Surgical procedures}

\section{Emergency debridement}

All patients were given emergency debridement. After successful anesthesia, the patient was put in the supine position, plenty of $0.9 \%$ saline, hydrogen peroxide and iodophor were used to flushing the wound, disposable negative pressure washing gun could be choose if the wound was deep and polluted seriously. Pneumatic tourniquets are available for operations about the root of patient's thigh and the lower limb may be prepared and draped before the tourniquet is applied. If necessary, the incision should be prolonged along the wound location to remove contaminated tissue and skin edges, inactivated

Table 1 General information

\begin{tabular}{|c|c|c|c|c|c|c|c|c|c|c|c|c|}
\hline \multirow[t]{2}{*}{ Group } & \multirow{2}{*}{$\begin{array}{l}\text { Patients } \\
\text { (n) }\end{array}$} & \multicolumn{2}{|c|}{ Gender } & \multirow{2}{*}{$\begin{array}{l}\text { Age } \\
\text { (years, } x \pm s \text { ) }\end{array}$} & \multicolumn{2}{|c|}{ Mechanism of injury } & \multicolumn{3}{|c|}{ Gustilo classification } & \multicolumn{3}{|c|}{ AO classification } \\
\hline & & Male & Female & & Traffic injuries & Others & 1 & II & III & $42-A$ & $42-B$ & $42-C$ \\
\hline A & 35 & 27 & 8 & $46.83 \pm 15.83$ & 25 & 10 & 4 & 12 & 19 & 13 & 16 & 6 \\
\hline B & 30 & 25 & 5 & $44.27 \pm 12.37$ & 21 & 9 & 7 & 11 & 12 & 11 & 14 & 5 \\
\hline C & 26 & 22 & 4 & $44.96 \pm 14.48$ & 19 & 7 & 3 & 7 & 16 & 11 & 11 & 4 \\
\hline$P$ & - & $>0.05$ & & $>0.05$ & $>0.05$ & & $>0.05$ & & & $>0.05$ & & \\
\hline
\end{tabular}

Group A: simple external fixator fixation

Group B: external fixator combined with plate-screw osteosynthesis

Group C: external fixator combined with k-wire intramedullary fixation 
or suspected inactivated tissue. Investigate the wound carefully and find out whether the fracture end is exposed and if there were vascular and nerve injuries, marked the injured vessels and nerves with silk thread, and reconstructed them after the fracture was fixed. The patients injured in $8 \mathrm{~h}$ were fixated according to the general condition after debridement. For patients who were injured over $8 \mathrm{~h}$, calcaneal traction was given temporarily, and fracture fixation should be completed within 7 days.

\section{Fracture stabilization}

Three groups of patients were treated respectively with simple external fixator (Group A), external fixator combined with plate-screw osteosynthesis (Group B), external fixator combined with $\mathrm{K}$-wire intramedullary fixation (Group C) for fracture reduction and fixation.

In group $\mathrm{A}$, closed reduction was performed first, fracture ends were antagonized traction and restored with the help of $\mathrm{C}$-arm. If the reduction is not ideal, cut a 3$4 \mathrm{~cm}$ incision for exposing fracture ends of tibia and cleaning soft tissue and blood clots embedded in the fracture site. Then the fracture end could be reduced by traction and temporary fixation assisted with boneholder or K-wire. After the initial reduction of the fracture, inserted screws into the proximal and distal segments of tibia fracture end, the calcaneus or the first metatarsal bone depending on the location of the fracture, installed the fixation clips for each screw and connected them with a biplanar external fixators. The $\mathrm{C}$-arm fluoroscopy was used to examine and adjust the reduction to be in good alignment, then the screw of the fixator was fastened completely. Fracture ends of fibula were not fixed (Fig. 2).

For patients in group $\mathrm{B}$, fracture ends of tibia were fixed with external fixator first in the same way with group A. Then an incision about $10 \mathrm{~cm}$ was made centered on the fracture ends of fibula, cut the skin and subcutaneous tissue layer by layer, peeled off the periosteum locally, exposed the fracture ends of fibula, checked the fracture situation, cleaned up the fracture ends and fixed the fracture reduction with bone-holder temporarily, then fixed the fractures with an appropriate length locked plate. The anteriorposterior and lateral views should both be checked and rotary restoration should be confirmed. Once functional reduction is accomplished, the locking screws are driven in (Fig. 3).

External fixation combined with $\mathrm{K}$-wire intramedullary fixation was conducted in group C. Firstly, fracture ends of fibula were fixed intramedullary with a K-wire. A 0.5 $\mathrm{cm}$ incision was made $2.0 \mathrm{~cm}$ above the tip of fibula, and a K-wire of $2.0-3.0 \mathrm{~mm}$ diameter was inserted retrograde into the fibular marrow cavity from the bottom to the top. If necessary, a hammer could be used to tap the tail of the Kirschner needle to help insert the needle.

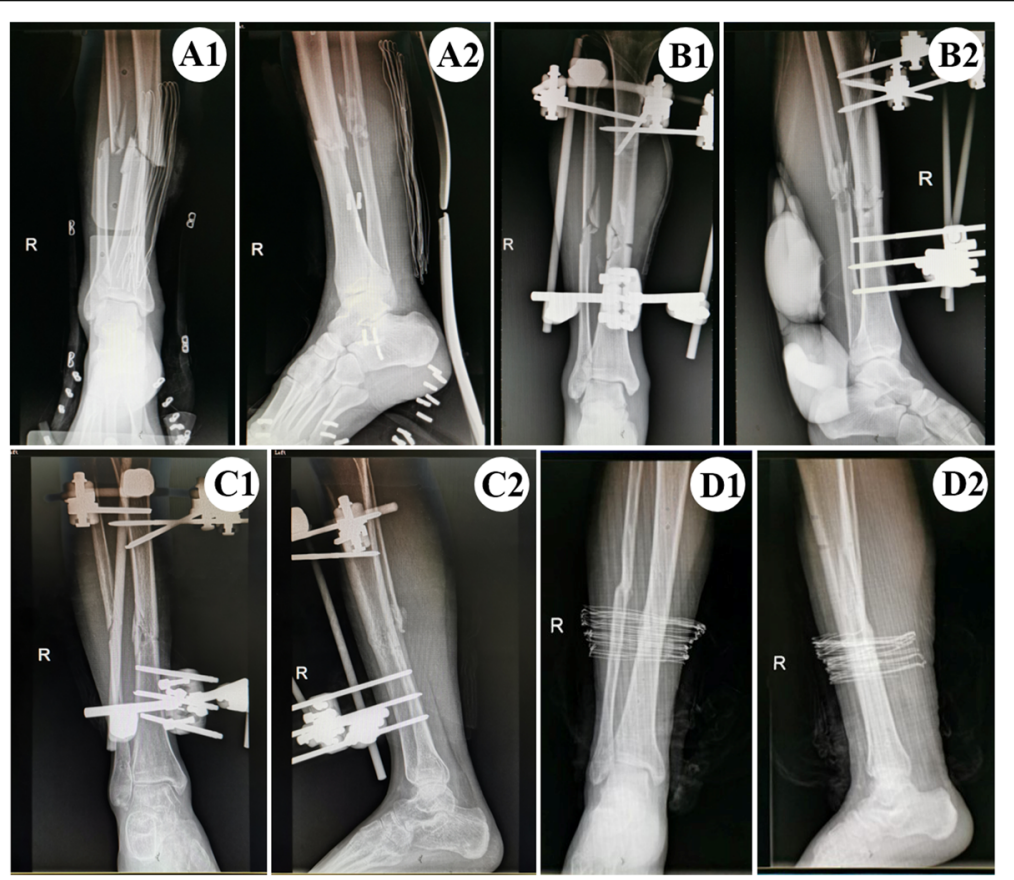

Fig. 2 A1-A2 Anteroposterior and lateral radiograph of distal tibiofibular fractures before operation. B1-B2 Bedside X-ray examination 2 days after operation (anteroposterior and lateral views). C1-C2 The fracture showed radiological signs of healing 7 months after operation (anteroposterior and lateral views). D1-D2 The external fixator was removed completely 10 months after operation (anteroposterior and lateral views) 
During the process of inserting the needle, the K-wire should be parallel to the long axis of the tibia, the multisegment fractures of fibula were restored in turn with the help of assistant. Adjust the K-wire under the C-arm examination until the fracture of the fibula was in good alignment. The tip of the K-wire should be $10.0 \mathrm{~cm}$ more passed through the proximal end of the fibula fracture so as to achieve an effective fixation. The tail of the needle is reflexed outside the skin for easy daily disinfection and care. After fibula fracture was fixed, external fixator was used to fix tibia fracture in the same way with group A (Fig. 4).

\section{Treatment of complications}

After the fracture was fixed, washing the wound with plenty of saline, then reconstructed the injured blood vessels and nerve. Made primary suture for Gustilo I and Gustilo II patients with less pollution and soft tissue contusion. The patients of type III A, type III B and type III $C$ were treated with partial tension reduction suture because of the large wound and serious pollution. Covered the wound with VSD membranes and connected to a negative pressure drainage tube. For patients with large area of skin and soft tissue defects, Shengjigao (Tianjin Hospital, Tianjin, China) was applied to the wound after 2 weeks from operation to promote rehabilitation. Flap transfer or skin grafting should be performed in the second stage after the improvement of the soft tissue condition of the wound.

\section{Postoperative treatment and follow-up}

All the patients were given routine antibiotics in the perioperative period to prevent infection, and postoperative analgesia, improving circulation, bone strengthening, prevention of thrombosis and other symptomatic supportive treatment. The wound was treated by dressing change or replacement of VSD regularly and the tail of the K-wire was disinfected with iodophor every day to prevent the infection of wound and pin tract. The patient's contact information was registered at the time of discharge, and the patient was reviewed periodically. Fracture healing of the tibial and fibula has been observed with X-ray diagnostic techniques. After $8 \sim 12$ weeks of follow-up, the K-wire was removed according to the status of external fixation and fracture healing. Later, the patients were followed-up every 3 months and the external fixator was removed when the clinical healing of the fracture was confirmed. During the subsequent visit, professional rehabilitation training guidance should be given according to the different stages of the patients' recovery. The patient's limb function was evaluated at the last follow-up.

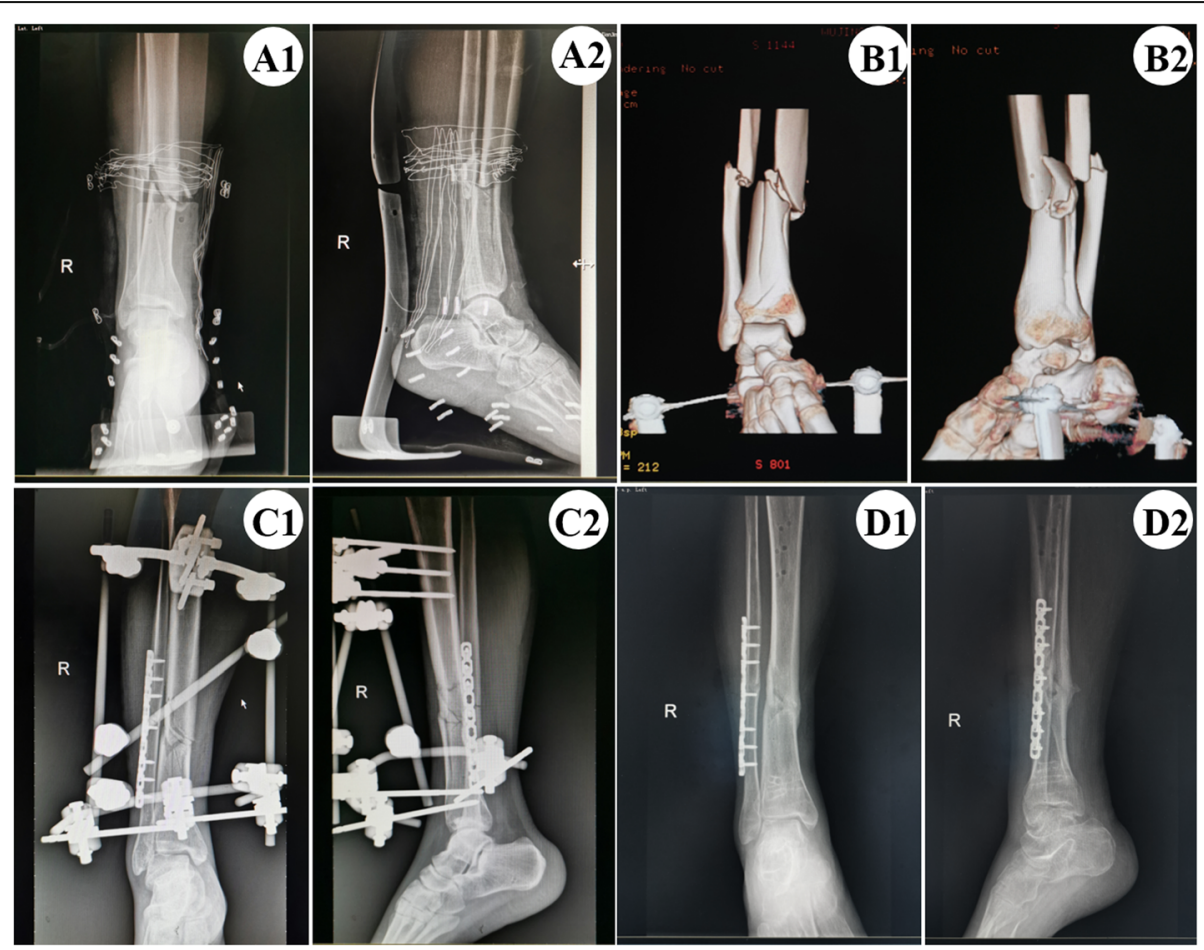

Fig. 3 A1-A2 Anteroposterior and lateral X-ray examination of distal tibiofibular fractures before operation. B1-B2 The 3D reconstruction image of CT scan after calcaneal traction. C1-C2 Bedside X-ray radiograph 2 days after operation (anteroposterior and lateral views). D1-D2 The fracture showed radiological signs of healing 6 months after operation and the external fixator was removed completely (anteroposterior and lateral views) 

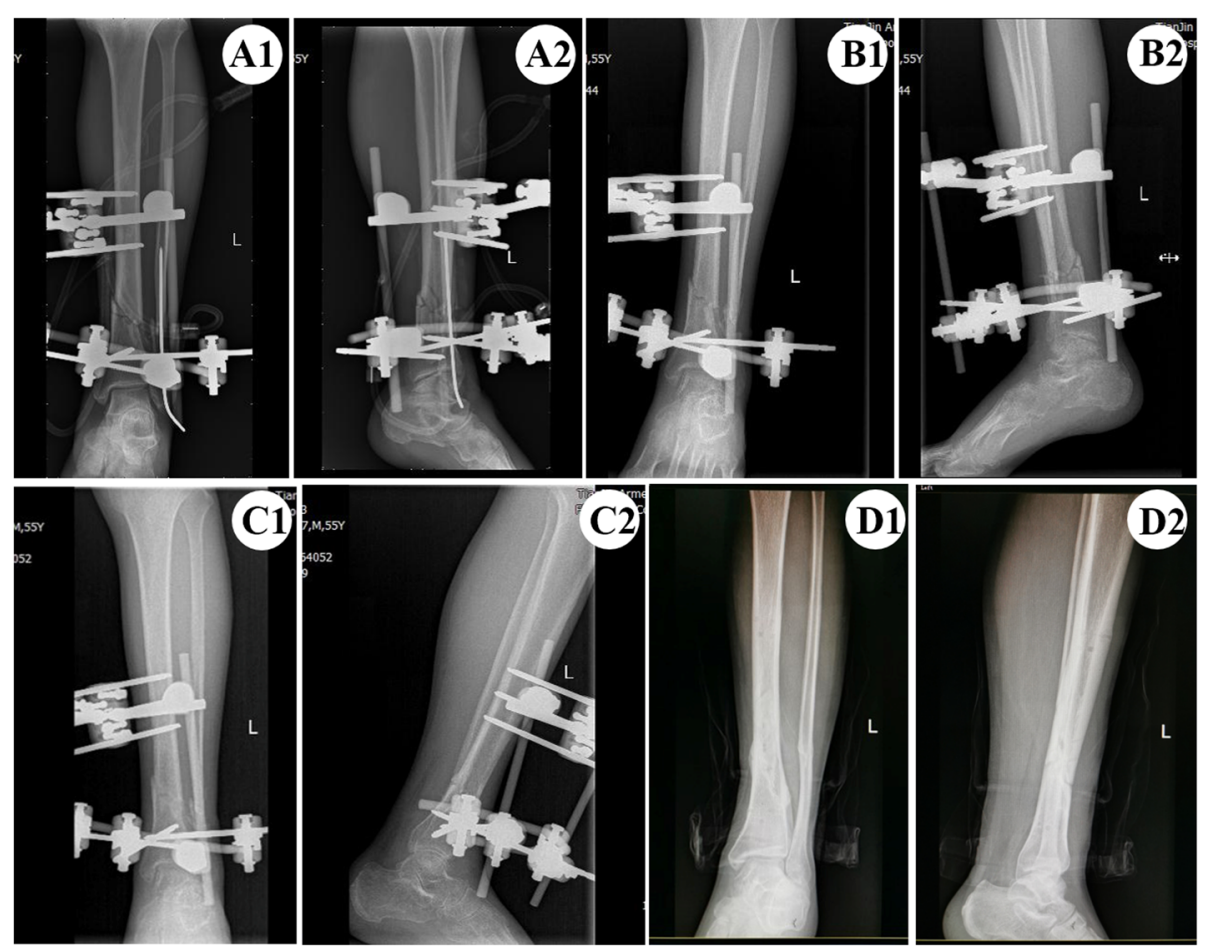

Fig. 4 A1-A2 Bedside X-ray radiograph 2 days after operation (anteroposterior and lateral views). B1-B2. The K-wire was removed 8 weeks after operation (anteroposterior and lateral radiograph). C1-C2 The fracture showed radiological signs of healing 5 months after operation (anteroposterior and lateral views). D1-D2 The external fixator was removed completely 8 months after operation (anteroposterior and lateral views)

\section{Data collection and analysis}

The operation time, intraoperative blood loss, surgical and implants costs, fracture healing time, postoperative complications and AOFAS scores at the last follow-up were recorded in the three groups. Fracture healing was assessed by X-ray examination and union was defined as dense callus bridging at least three of four cortices on positive and lateral X-ray examination. Delayed union was defined as radiographic union after $>8$ months. Nonunion was defined as lack of any healing within 12 months [15]. Data analysis was performed by SPSS software, version 25.0 (SPSS, Inc., Chicago, IL, USA). Continuous variables were expressed as mean \pm SD and differences in continuous variables among groups were examined using analysis of variance (ANOVA) and repeated measure of ANOVA. Pearson's chisquared analysis ( $\chi^{2}$ test) and Fisher's exact test were used for categorical variables. The level of significance was set at $P<0.05$.

\section{Results}

In this study, 87 cases were followed up regularly and 4 cases were lost. The follow-up period ranged from 5 to 35 months, with an average of 14.2 months. Four patients who were lost to follow up because they all came from other places. After the operation, the patients returned to the local hospital for further treatment. The results are presented in Table 2.

\section{Discussion}

Open double fractures of the distal tibia and fibula are complex injuries, if not treated properly, they may cause delayed union or nonunion of fractures, severe cases may lead to traumatic arthritis, which seriously affects the function of ankle joint. In 2015, Professor Raman Mundi et al. [3] published an update of the treatment guidelines for open tibial fractures in JBJS REV magazine. At present, intramedullary nail is recommended for open tibial shaft fractures, but the incidence of ankle stiffness, residual ankle pain and traumatic arthritis after intramedullary nail fixation is high. In addition, intramedullary nail has poor fixation effect on distal tibial comminuted fractures. Compared with the intramedullary nail, composite external fixator is flexible in assembly, simple in operation, short in operation time, and less in intraoperative blood loss. The external fixator can perform compression fixation, stretch fixation and neutral fixation according to different types of tibial-fibular fractures. It is a limited elastic fixation, which reduces the stress shielding of static locking fixation, and is 


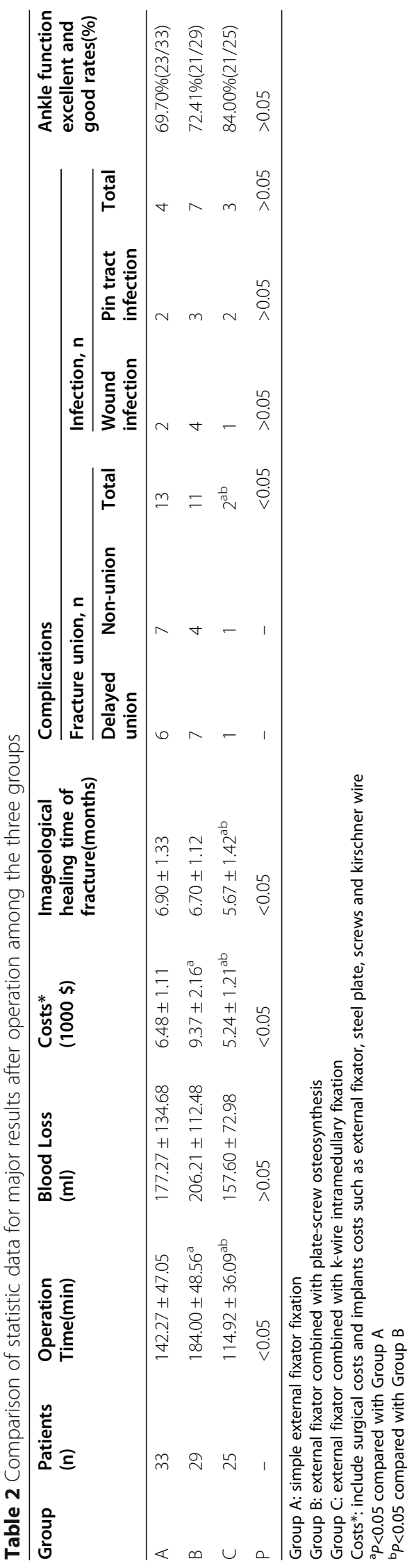


beneficial for the fretting of the longitudinal axis of the shaft at the same time. As a result, it can promote the healing of the fracture by making the fracture end get physiological stress.

However, pin tract infections are the big problem which is commonly occur in children with additional trauma and the people lack of selfcare [16]. So, external fixator is traditionally used as temporary fixator for open tibia and fibula fracture, which requires second-stage operation to be converted to internal fixation $[17,18]$. In recent years, many studies have shown that external fixator can also be used for definitive fixation of open tibia and fibula fractures [1922]. Some research reported that external fixation showed similar results to intramedullary nailing for treatment of open fractures of open tibia and fibula in terms of infection rate, malalignment, bone healing and quality of life [23-25]. The other researchers found that compared with simple external fixation, external fixation combined with limited internal fixation is an effective and safe alternative for management of open tibial diaphyseal fractures. It provides superior initial reduction, better stability and decreases the risk of inferior alignment and delayed union without increasing the risk of infection [26-28].

Recently, the role of fibula has been paid more attention by surgeons. Research shows that fibula bears $6.4 \%$ of body weight in ankle neutral position and the number can be more in ankle dorsiflexion or valgus. The stress distribution of medial tibia is larger than that of lateral tibia under normal physiological load, however when the fibula loses its continuity, the stress distribution will concentrate on the outside of the tibia [7]. The change of the stress distribution of the tibia will make the negative gravity line move out and cause ankle joint disorder. Over-syndesmotic treatment of the fibula fracture can make tibia osteosynthesis more efficient and improve the outcome [29]. Therefore, the fixation of fibula is according with the principle of biomechanics [30].

Through the comparative study of three different fixation methods of fibula combined with tibia external fixation, it was found that external fixator combined with plate-screw osteosynthesis in the treatment of open fracture of distal tibia and fibula prolonged the operation time, but had no obvious advantages in promoting fracture healing, reducing postoperative complications and functional recovery of affected limbs. The good news is that the K-wire group shortened the operation time and fracture healing time, reduced the costs and complications of fracture healing when compared with the other two groups. However, there was no significant difference among the three groups in terms of intraoperative blood loss, postoperative infection complications and the score of ankle function. The main reason led to this situation may be that the open fractures of distal tibia and fibula was often caused by high-energy trauma, which usually accompanied with other partial fractures and severe soft tissue contusions.

K-wire was first introduced as an internal fixation implant in 1909 by Martin Kirschner and it had been used for more than 110 years in orthopedic surgery [31]. Today K-wire is commonly used as a kind of temporary fixation device in clinic, however it can also been used as definitive fixator in displaced metacarpal shaft fractures, clavicle fractures and paediatric tibial shaft fractures [32-34]. The bone marrow cavity of fibula is narrow and irregular in shape, so the K-wire can be used to fix fibula fracture according to the principle of multipoint fixation [35]. Its advantages are as follows: first, no reamed medulla cavity, no peeling of periosteum, no destruction of the original hematoma at the fracture end, no aggravation of secondary damage to the skin, soft tissue and blood supply at the fracture site. It reduces complications of skin and soft tissue effectively and reflects the concept of minimally invasive treatment of fractures. Secondly, K-wire intramedullary fixation is easy to operate and does not require special equipment, it can be removed out at clinic without hospitalization. Thirdly, K-wire had lower economic cost but higher cost-effectiveness ratio when compared with locked plate and elastic intramedullary nail. Fibular K-wire intramedullary fixation conforms to the concept of biological fixation (BO) [36], whose core idea was to protect the blood supply of the fracture end, it didn't emphasize anatomical reduction, but to seek a balance between the stability of the fracture and the blood supply of local soft tissue. This fixation method belongs to elastic fixation, which didn't require very strong fixation, but can reduce the stress shielding of tibial healing. In addition, micromotion in elastic fixation of fracture ends can promote revascularization, rapid calcification of callus and the formation of related osteogenic factors, thus promoting the healing of fibular fractures. External fixator combined with Kwire had an excellent fixation effect in fixing comminuted distal tibial fracture. It can restore the continuity of fibula by K-wire and reduce the weight of tibia. Percutaneous k-wire fixation is a minimally invasive method and far away from the fracture end, thus it can maximize the protection of periosteum and soft tissue blood supply at the fracture site, and avoid the destruction of intramedullary nail fixation on the blood supply of the medullary cavity, which conforms to the concept of damage control orthopedics (DCO) [37]. More important, combined fixation increased the stability of tibial fixation, reduced the excessive stress damage of fracture end, and improved the healing rate of tibia fracture.

In conclusion, the importance of fibular fixation in the treatment of open fracture of distal third tibia and fibula 
has been accepted by more and more surgeons, but the method of fixation has not reached a consensus. Proper fibular internal fixation can promote the healing of tibial fracture and maintain the stability of lower tibiofibular joint and ankle joint. Compared with simple external fixation and external fixation combined with plate-screw osteosynthesis, external fixation combined with $\mathrm{K}$-wire has less trauma, shorter operation time, lower costs, faster fracture healing and better healing quality of fracture in the treatment of open fracture of distal tibia and fibula. This study also has some limitations, it is a retrospective case study with small sample size, lack of prospective cohort study and randomized controlled study. The results need to be further confirmed by large sample clinical studies.

\section{Conclusion}

Compared with simple external fixator fixation and external fixator combined with plate-screw osteosynthesis, external fixator combined with K-wire intramedullary fixation shorten the operative time and fracture healing time, reduced costs and complications of fracture healing, while the blood loss, infection complications and ankle function recovery showed no difference with the other two groups. External fixator combined with plate-screw osteosynthesis had no advantage in treating extra-articular open fractures of distal tibia and fibula when compared with simple external fixation.

\section{Abbreviations \\ K-wire: Kirschner wire; AOFAS: American Orthopaedic Foot and Ankle surgery; DCP: Dynamic compression bone plate; MIPPO: Minimally invasive percutaneous plate osteosynthesis; VSD: Vacuum sealing drainage devices; ANOVA: Analysis of variance; BO: Biological fixation; DCO: Damage control orthopedics}

\section{Acknowledgments}

We are very grateful for the support of the information department and imaging department who helped collect patient data.

\section{Authors' contributions}

DD S, D L and ML S designed the study protocol. K Z and J C collected and analyzed the clinical data of patients. DD S wrote the first draft of the manuscript. ML S and LL G provided revision for intellectual content and final approval of the manuscript. All authors read and approved the final manuscript.

\section{Funding}

This study was supported by National Natural Science Foundation of China (grant number: 11572222).

\section{Availability of data and materials}

Not applicable.

\section{Ethics approval and consent to participate}

The study was approved by Ethics Committee of Characteristic Medical center of Chinese People's Armed Police (Ethical approval number: 2018-0004). All participants provided written informed consent prior to initiation of study procedures.

\section{Consent for publication}

The manuscript is approved by all authors for publication.

\section{Competing interests}

All the authors have no conflict of interest.

\section{Author details}

${ }^{1}$ Department of Orthopedic, Characteristic Medical center of Chinese People's Armed Police Force, No. 220 Cheng Lin Road, Tianjin 300171, China. ${ }^{2}$ Logistics University of People's Armed Police, Tianjin 300300, China. ${ }^{3}$ School of Mechanical Engineering, Tianjin University of Technology, No. 391 Bin Shui West Road, Tianjin 300384, China.

Received: 18 May 2020 Accepted: 26 November 2020

Published online: 04 January 2021

\section{References}

1. Torino D, Mehta S. Fibular fixation in distal tibia fractures: reduction aid or nonunion generator? J Orthop Trauma. 2016;30(Suppl 4):S22-5.

2. Pogliacomi F, Schiavi P, Calderazzi F, Ceccarelli F, Vaienti $E$. When is indicated fibular fixation in extra-articular fractures of the distal tibia? Acta Biomed. 2019:89(4):558-63.

3. Mundi R, Chaudhry H, Niroopan G, Petrisor B, Bhandari M. Open tibial fractures: updated guidelines for management. JBJS Rev. 2015;3(2): 01874474-201503020-00003.

4. Berlusconi M, Busnelli L, Chiodini F, Portinaro N. To fix or not to fix? The role of fibular fixation in distal shaft fractures of the leg. Injury. 2014;45(2):408-11.

5. Taylor BC, Hartley BR, Formaini N, Bramwell TJ. Necessity for fibular fixation associated with distal tibia fractures. Injury. 2015;46(12):2438-42.

6. Bonnevialle P, Lafosse JM, Pidhorz L, Poichotte A, Asencio G, Dujardin F. Distal leg fractures: how critical is the fibular fracture and its fixation? Orthop Traumatol Surg Res. 2010;96(6):667-73.

7. Vasanad GH, Antin SM, Akkimaradi RC, Policepatil P, Naikawadi G. The role of fibular fixation in distal tibial fractures. J Clin Diagn Res. 2016;10(4):Rc12-4.

8. Attal R, Hansen M, Kirjavainen M, Bail H, Hammer TO, Rosenberger R, Höntzsch D, Rommens PM. A multicentre case series of tibia fractures treated with the Expert Tibia Nail (ETN). Arch Orthop Trauma Surg. 2012; 132(7):975-84

9. Avilucea FR, Triantafillou K, Whiting PS, Perez EA, Mir HR. Suprapatellar intramedullary nail technique lowers rate of malalignment of distal tibia fractures. J Orthop Trauma. 2016;30(10):557-60.

10. Javdan M, Tahririan MA, Nouri M. The role of fibular fixation in the treatment of combined distal tibia and fibula fracture: a randomized, control trial. Adv Biomed Res. 2017;6:48.

11. Rollo G, Falzarano G, Ronga M, Bisaccia M, Grubor P, Erasmo R, Rocca G, Tomé-Bermejo F, Gómez Garrido D, Pichierri P, et al. Challenges in the management of floating knee injuries: results of treatment and outcomes of 224 consecutive cases in 10 years. Injury. 2018;50(Suppl 4):S30-8.

12. Fortina M, Maniscalco P, Carulli C, Meccariello L, Colasanti G, Carta S. Jockey injuries during the Siena "Palio". A 72-year analysis of the oldest horse race in Italy. Injury. 2019:50(Suppl 4):S56-9.

13. Grubor P, Milicevic S, Grubor M, Meccariello L. Treatment of bone defects in war wounds: retrospective study. Med Arch (Sarajevo, Bosnia and Herzegovina). 2015;69(4):260-4.

14. Khan MS, Giacomo L, Bisaccia M, Azzam W, Jatoi A, Rollo G, Meccariello L. Ilizarov technique, satisfactory outcome with limited resources. Clin Cases Miner Bone Metab. 2018;15:221-6.

15. Bhandari M, Fong K, Sprague S, Williams D, Petrisor B. Variability in the definition and perceived causes of delayed unions and nonunions: a crosssectional, multinational survey of orthopaedic surgeons. J Bone Joint Surg Am. 2012;94(15):e1091-6.

16. Franzese R, Conte M, Gagliardo N, Pieretti G. Children vs elderly in orthopedic surgery site of infection. Are there difference? Experience of a high volume plastic surgeon consultant. Acta Medica Salin. 2020;49(2):24-9.

17. Potter JM, van der Vliet QMJ, Esposito JG, McTague MF, Weaver M, Heng M. Is the proximity of external fixator pins to eventual definitive fixation implants related to the risk of deep infection in the staged management of tibial pilon fractures? Injury. 2019;50(11):2103-7.

18. Ketz J, Sanders R. Staged posterior tibial plating for the treatment of orthopaedic trauma association 43C2 and 43C3 tibial pilon fractures. J Orthop Trauma. 2012;26(6):341-7.

19. Dai J, Wang X, Zhang F, Zhu L, Zhen Y. Treatment of distal metaphyseal tibia fractures using an external fixator in children. Medicine (Baltimore). 2019;98(36):e17068. 
20. Liu L, Tan G, Luan F, Tang X, Kang P, Tu C, Pei F. The use of external fixation combined with vacuum sealing drainage to treat open comminuted fractures of tibia in the Wenchuan earthquake. Int Orthop. 2012;36(7):1441-7.

21. Atef A, El Tantawy A. Open unstable metaphyseo-diaphyseal fractures of the tibia in adolescents: treatment by flexible intramedullary nails augmented by external fixator. Int Orthop. 2015;39(5):921-6.

22. Cui X, Chen H, Rui Y, Niu Y, Li H. Two-stage open reduction and internal fixation versus limited internal fixation combined with external fixation: a meta-analysis of postoperative complications in patients with severe Pilon fractures. J Int Med Res. 2018;46(7):2525-36.

23. Rodrigues FL, de Abreu LC, Valenti VE, Valente AL, da Costa Pereira Cestari $\mathrm{R}$, Pohl PH, Rodrigues LM. Bone tissue repair in patients with open diaphyseal tibial fracture treated with biplanar external fixation or reamed locked intramedullary nailing. Injury. 2014;45(Suppl 5):S32-5.

24. RV OT, Gary JL, Reider L, Bosse MJ, Gordon WT, Hutson J, Quinnan SM, Castillo RC, Scharfstein DO, Mackenzie EJ. A prospective randomized trial to assess fixation strategies for severe open tibia fractures: modern ring external fixators versus internal fixation (FIXIT study). J Orthop Trauma. 2017; 31(Suppl 1):S10-s17.

25. Fang $X$, Jiang L, Wang Y, Zhao L. Treatment of Gustilo grade III tibial fractures with unreamed intramedullary nailing versus external fixator: a meta-analysis. Med Sci Monit. 2012;18(4):Ra49-56.

26. Hao ZC, Xia Y, Xia DM, Zhang YT, Xu SG. Treatment of open tibial diaphyseal fractures by external fixation combined with limited internal fixation versus simple external fixation: a retrospective cohort study. BMC Musculoskelet Disord. 2019;20(1):311.

27. Sun LJ, Wu ZP, Guo XS, Chen H. Management of distal third tibial fractures: comparison of combined internal and external fixation with minimally invasive percutaneous plate osteosynthesis. Int Orthop. 2014;38(11):2349-55.

28. Tu KK, Zhou XT, Tao ZS, Chen WK, Huang ZL, Sun T, Zhou Q, Yang L. Minimally invasive surgical technique: percutaneous external fixation combined with titanium elastic nails for selective treatment of tibial fractures. Injury. 2015;46(12):2428-32.

29. Falzarano G, Pica G, Medici A, Rollo G, Bisaccia M, Cioffi R, Pavone M, Meccariello L. Foot loading and gait analysis evaluation of nonarticular Tibia Pilon fracture: a comparison of three surgical techniques. J Foot Ankle Surg. 2018;57(5):894-8

30. Varsalona R, Liu GT. Distal tibial metaphyseal fractures: the role of fibular fixation. Strat Traum Limb Recon. 2006;1 (1):42-50.

31. Franssen BBGM, Schuurman A, Molen A, Kon M. One century of Kirschner wires and Kirschner wire insertion techniques: a historical review. Acta Orthop Belg. 2010;76:1-6.

32. van Bussel EM, Houwert RM, Kootstra TJM, van Heijl M, Van der Velde D, Wittich P, Keizer $J$. Antegrade intramedullary Kirschner-wire fixation of displaced metacarpal shaft fractures. Eur J Trauma Emerg Surg. 2019;45(1):65-71.

33. Sahu RL, Ranjan R. Fracture union in percutaneous Kirschner wire fixation in paediatric tibial shaft fractures. Chin J Traumatol. 2016;19(6):353-7.

34. Bakota B, Chan G, Staresinic M, Rajput V, Phadnis J, Korac Z. Safe intramedullary fixation of displaced midshaft clavicle fractures with $2.5 \mathrm{~mm}$ Kirschner wires - technique description and a two-part versus multifragmentary fracture fixation outcome comparison. Injury. 2017; 48(Suppl 5):S27-s33.

35. Dombroski D, Scolaro JA, Pulos N, Beingessner DM, Dunbar R, Mehta S. Fibular fracture stabilization with a guidewire as supplementary fixation in tibia fractures. Am J Orthop (Belle Mead NJ). 2012;41(11):506-9.

36. Gerber C, Mast JW, Ganz R. Biological internal fixation of fractures. Arch Orthop Trauma Surg. 1990;109(6):295-303.

37. Gasser B, Tiefenboeck TM, Boesmueller S, Kivaranovic D, Bukaty A, Platzer P. Damage control surgery - experiences from a level I trauma center. BMC Musculoskelet Disord. 2017;18(1):391.

\section{Publisher's Note}

Springer Nature remains neutral with regard to jurisdictional claims in published maps and institutional affiliations.

Ready to submit your research? Choose BMC and benefit from:

- fast, convenient online submission

- thorough peer review by experienced researchers in your field

- rapid publication on acceptance

- support for research data, including large and complex data types

- gold Open Access which fosters wider collaboration and increased citations

- maximum visibility for your research: over $100 \mathrm{M}$ website views per year

At BMC, research is always in progress.

Learn more biomedcentral.com/submissions 